\title{
Moho Depth Derived from Gravity Data in the Taiwan Strait Area
}

\author{
Hsien-Hsiang Hsieh, Horng-Yuan Yen ${ }^{*}$, and Min-Hung Shih \\ Institute of Geophysics, National Central University, Jhongli, Taiwan, ROC
}

Received 22 July 2008, accepted 5 March 2009

\begin{abstract}
We have constructed a regional Bouguer gravity anomaly map using marine and land data from Taiwan and the Chinese province of Fuchien, as well as SEASAT altimetry-derived gravity data for the Taiwan Strait and its surrounding area. The map shows isogals trending generally in a NE-SW direction, conforming with the overall shallower geological strike of the strait. Removing gravity effects generated by the water layer and seafloor topography, the regional Bouguer gravity anomaly is obtained, reflecting the subsurface structure. Moho depth is then computed by the Parker-Oldenburg iterative method from the regional Bouguer gravity data set. Over the strait area, the geometry of the Moho relief is smooth with an average depth of about $30 \mathrm{~km}$, except for the Penghu uplift. Moho depth is shallower in the Taiwan Strait and thickens toward both sides of the strait. The relatively shallower Moho depth, reaching up to $28 \mathrm{~km}$, is convex upward underneath the Penghu uplift.
\end{abstract}

Key words: Gravity, Moho depth, Taiwan Strait

Citation: Hsieh, H. H., H. Y. Yen, and M. H. Shih, 2010: Moho depth derived from gravity data in the Taiwan Strait area. Terr. Atmos. Ocean. Sci., 21, 235-241, doi: 10.3319/TAO.2009.03.05.01(T)

\section{INTRODUCTION}

The Taiwan Strait is situated on the continental shelf off the southeast China coast between the East China Sea and the South China Sea, trending NE-SW (Fig. 1). Regional stresses of the Taiwan Strait area can be considered as a result of two tectonic forces. The first is the compressional stress related to the arc-continent collision between the Philippine Sea plate and the Eurasian plate, and the second is the extensional stress related to the opening of the South China Sea to the south. Under these two mechanisms, the crust of the Taiwan Strait is formed by a complex structure of uplifting, normal faulting, and volcanic intrusion (Gao and Huang 1994). A center of thinning lithosphere and asthenosphere upwelling has been identified on the western side of Taiwan based upon geochemistry interpretations (Chung et al. 1994). The crust of the Taiwan Strait area can be considered as a part of the Eurasian continent slightly deformed due to the arc-continent collision. The Moho dips slightly from west to east shown by $\mathrm{P}_{n}$ velocity study (Huang et al. 1998).

From a tectonic point of view, there are several alternating basins and uplifts in the Taiwan Strait. The Kuanyin

\footnotetext{
* Corresponding author

E-mail:yenhy@earth.ncu.edu.tw
}

uplift and Peikang High alternate with the TaichungTaihsi and Tainan basins located on the east side of the strait. The Taichung-Taihsi and Tainan basins have accumulated dense sediments of great thickness due to rapid subsidence (Chou 1991) and have extended to western Taiwan separated by the Peikang High. The Tainan basin, with sediments more than $6000 \mathrm{~m}$ thick, is characterized by extensional normal faults trending mainly in the NE-SW and E-W directions (Yang et al. 1991). The Taiwan Strait, as a part of the South China Sea margin, consists of the Paleocene syn-rift sequence and the Neocene-Quaternary post-rift sequence (Teng 1992). A number of Paleocene fault-bounded troughs, including the Nanjihtao basin and Penghu basin, developed on the thinning Mesozoic basement (Sun 1982). Both the syn-rift and postrift sequences are composed of paralic and shallow marine deposits derived from southeastern China. The half graben is the principal feature in the rifting continental margin (Rosendahl 1987). As expected, the early Tertiary sediments are primarily confined to the half grabens and form a thick asymmetrical wedge. These wedge-shaped sequences, such as Nanjihtao and Penghu basins along the Taiwan Strait, are comprised of thick sediments (Sun 1982; Hsiao et al. 1991; Yu and Huang 1994). 


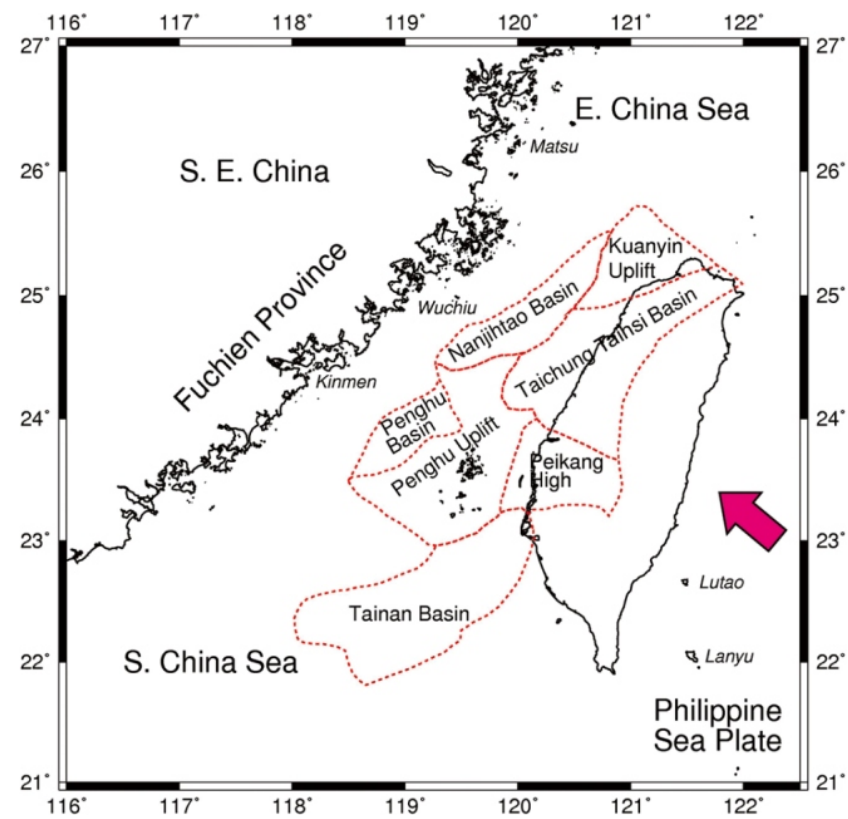

Fig. 1. Map showing the geological and tectonic settings near Taiwan. The Philippine Sea plate moves toward the northwest relative to the Eurasia plate at about $8 \mathrm{~cm} \mathrm{yr}^{-1}$ (big red arrow). Dashed lines show the major geological structures of the Taiwan Strait (by a series of basins: the Taichung-Taihsi, Nanjihtao, Penghu, and Tainan Basins; the Kuanyin and Penghu Uplifts; and the Peikang High).

As mentioned, not a lot of geological and geophysical investigations in parts of the Taiwan Strait have been reported in the past (Sun 1985; Chen and Nakamura 1992; Yu 1993; Chung et al. 1994; Gao and Huang 1994; Kao and Wu 1996; Huang et al. 1998, Chen et al. 2005). Because access to the Taiwan Strait as a whole has been limited for years due to political reasons, the overall tectonics of the strait, derived from tomography results and detailed seismic profiles, remains obscure, even though it forms an important part close to the collision boundary. Although three local networks, Fuchien Seismic Network (FJN), Broadband Array in Taiwan for Seismology (BATS), and the Central Weather Bureau Seismic Network (CWBSN) are located on both sides of the strait, very few seismic constraints on the tectonic structure of this area are available. Recently, Ai et al. (2007) utilized seismic waveforms recorded by the above three networks to illustrate the 2-D crustal and upper mantle structures of two parallel profiles across the southeastern China region by using common converted point stacking of receiver functions. Regrettably, the shallower structures beneath the Taiwan Strait within those two profiles could not be solved due to sparse seismic data.

Up to now, gravity data over the Taiwan Strait are currently the most integrated and provide the best geophysical data coverage. Fundamental information regarding structural configuration, such as Moho relief, generally can be inverted by using essential gravity data. For simplicity, we as- sume a density contrast between the two media, i.e., crust and mantle, to obtain the gross feature related to the depth of the interface. In this study, Moho depth in the Taiwan Strait area is inverted using a MATLAB source code 3DINVER.M (Gómez-Ortiz and Agarwal 2005) from an integrated new gravity data set. The result gives us a preliminary understanding of crustal strcture and deformation beneath the Taiwan Strait area.

\section{DATA COMPILATION AND BOUGUER ANOMALY MAP}

Gravity measurements and analyses are particularly useful as a reconnaissance tool for a large tectonic region. A high-resolution regional gravity map over the Taiwan Strait $\left(21-27^{\circ} \mathrm{N}\right.$ and $\left.116-122.5^{\circ} \mathrm{E}\right)$ can help us understand its tectonic signature. There is, therefore, a need to compile a gravity map that encompasses the entire strait region. In this study, the gravity data are compiled from four sources: (1) 603 Island-wide gravity stations have been established by the Institute of Earth Sciences, Academia Sinica (Yen et al. 1995b) since 1980. Several tens of measurements from the offshore islands, such as Penghu, Lutao, Lanyu, and Pengchiayu (Fig. 1), have since been added to the data set. (2) There are several tens of ship tracks in the National Geophysical Data Center (NGDC) archive of the NOAA, USA, with continuing gravity observations of offshore Taiwan. Those data with obvious noise, large time gaps and suspicious glitches or drifts in the digital records are first rejected. Any cruise without a base tie is useful only if it yields consistent crossover differences with all intercepting, calibrated cruises. This means that for the crossover differences, the root-mean-squares deviation from the mean must be small compared to the mean itself. Thirteen such ship tracks plus similar two from the Chinese Petroleum Company are retained as suitable for the study. Three cruises mentioned above are analyzed through the crossover analysis. Following this strategy, most gravity lines are tied to the MW9006 in the southern area and to the POP 1 and 2 to the northeast of Taiwan (Yen et al. 1995a). (3) To maintain a reasonable extrapolation of the strait area where no ship tracks were present, the SEASAT gravity data was used to fill data gaps during the overall compilation (Haxby 1987). These data, given at $1 / 4^{\circ}$ grids, are derived from the SEASAT satellite geodetic mission verified with the gravity data at the Penghu islands, and are therefore characterized by relatively smooth variations. (4) The gravity data of Fuchien Province, China was digitized from the Bouguer gravity anomaly map of the South and East China Seas and adjacent regions, as compiled by the Ministry of Geology and Mineral Resources, People's Republic of China and published by the Geological Publishing House (Liu 1992).

It is also time-consuming, tedious and difficult work to integrate gravity data from so many sources (inland, off- 
shore islands, marine, and satellite data). Details of gravity compilation procedure and data quality for items (1) to (3) have been described by Yen et al. (1995a, b). To ensure the reliability of the Bouguer anomaly of Fuchien Province, we carried out a gravity survey at the offshore islands of Kinmen, Wuchiu, and Matsu (Fig. 1) located nearby Fuchien's provincial coast to correct their Bouguer anomaly value. These data sets were accurately calibrated using the International Gravity Standardization Net 1971, and the gravity anomaly were referenced to Geodetic Reference System 1967 , thus facilitating the construction of a regional map that includes both land gravity data (Bouguer anomaly) and marine gravity data (free-air anomaly). The compiled gravity anomaly map for the Taiwan Strait is shown in Fig. 2a. The isogals trend generally in a NE-SW direction, in consonance with the overall shallower geological strike of the strait. Conspicuous negative anomalies cover Fuchien Province and Western Taiwan, whereas positive anomalies dominate the Taiwan Strait. An anomaly high over the Penghu islands and their southern part reaches a maximum value of $60 \mathrm{mgal}$. Taichung-Taihsi, Tainan, Nanjihtao, and Penghu basins show relative gravity lows due to thick sediments. It is obvious that dominants influence over those gravity anomalies are the sediment and water layers. To better suppress gravity effects due to the shorter wavelength attributable to the water layer and submarine topography, Bouguer, and terrain corrections should be considered for the marine gravity data. Fortunately, the average depth of the water layer is about $100 \mathrm{~m}$, and the topography of the seafloor is not rugged over the Taiwan Strait. The water layer can be replaced directly by the crust with a density of $2.67 \mathrm{~g} \mathrm{~cm}^{-3}$ by using a simple integration process, and the terrain correction of the seafloor topography can be neglected. The density of the Penghu islands, composed of extensive basalt flows, is close to the average crustal density $\left(2.67 \mathrm{~g} \mathrm{~cm}^{-3}\right)$. To obtain Moho depth, corresponding longer wavelength anomalies, the regional Bouguer gravity anomaly (Fig. 2b) is calculated by the Griffin method (1949). A semicircular gravity high, with a maximum value of $180 \mathrm{mgal}$, manifests itself as a prominent, continuous high extending northerly to the Penghu islands from the southern border of the map. This anomaly is most probably caused by the oceanic crust beneath the southern strait and high-density extrusive basalt outcrop on the Penghu islands.

\section{THEORY AND ALGORITHM}

The program, based on the Parker-Oldenburg method, has been presented by Gómez-Ortiz and Agarwal (2005) for computing $3 \mathrm{D}$ geometry of the density interface from a gridded gravity anomaly. This procedure is based on a relationship between the Fourier transform of the gravity anomaly and the sum of the Fourier transform of the interface topography. Given the average depth of the interface boundary and density contrast between the two media and the geological control depths described above, the 3-D geometry of the interface is iteratively calculated.
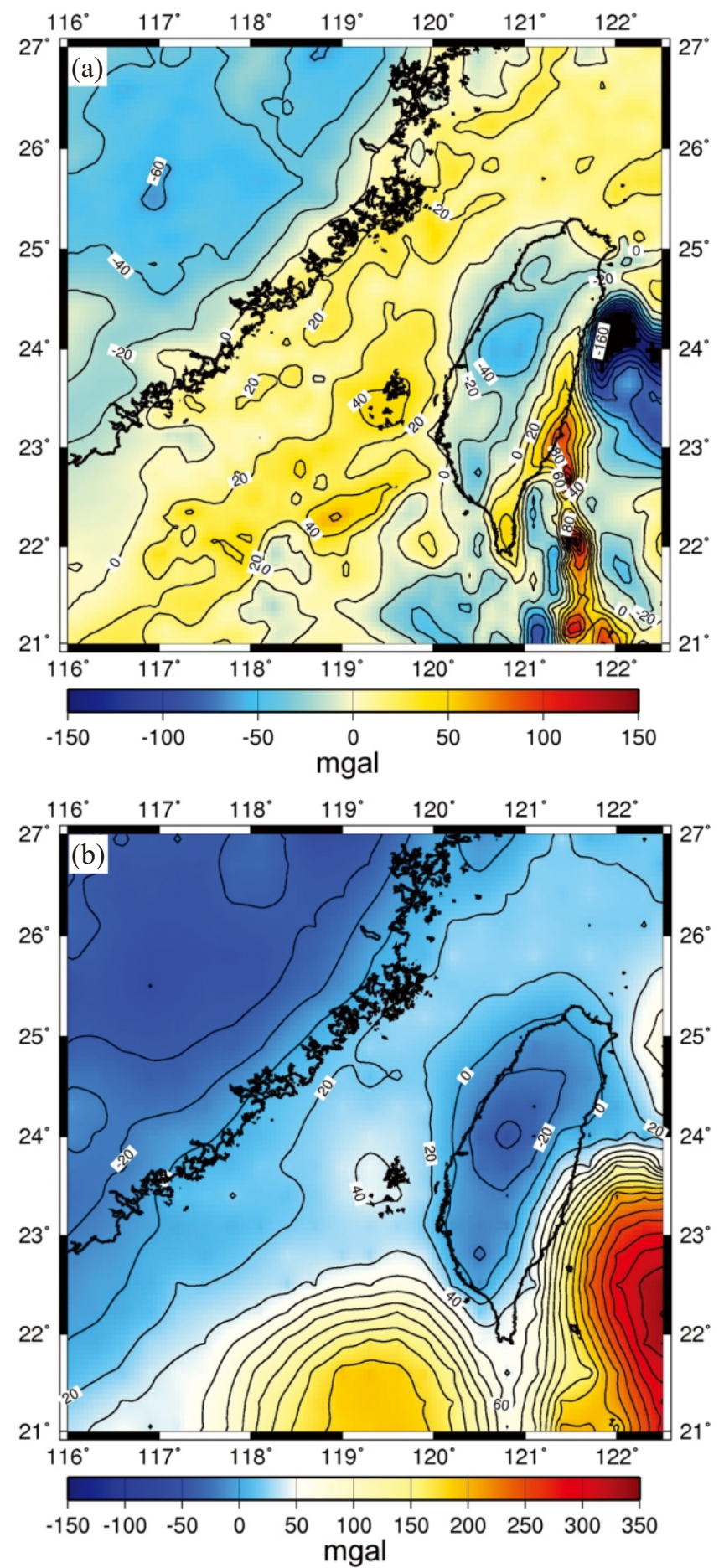

Fig. 2. (a) Gravity anomaly map of the Taiwan Strait area with a 20 mgal contour interval. The map is obtained by joining the interpolated land gravity data (Bouguer anomaly) and the marine data (free-air anomaly) on a $1 / 12^{\circ}$ grid. The isogals trend generally to the NE-SW direction, consistent with the overall shallower geological strike of the strait. (b) After replacing the sea-water layer to the crust, the regional Bouguer gravity anomaly map was obtained. The contour interval is $20 \mathrm{mgal}$. 
The equation described by Parker (1973) is used to calculate the homogeneous layer with an uneven boundary generated by density contrasts. Using the Fourier transform of the gravity anomaly, we have:

$F(\Delta g)=-2 \pi G \rho e^{\left(-k z_{0}\right)} \sum_{n=1}^{\infty} \frac{k^{n-1}}{n !} F\left[h^{n}(x)\right]$

where $F(\Delta g)$ is the Fourier transform of the gravity anomaly; $G$ is the gravitational constant; $\rho$ is the density contrast across the interface; $k$ is the wave number; $h(x)$ is the depth to the interface (positive downwards); and $z_{0}$ is the average depth of the horizontal interface.

We compute the undulating interface depth from gravity anomaly data, following Oldenburg (1974) in a rearranged Eq. (1):

$F[h(x)]=-\frac{F[\Delta g(x)] e^{\left(k z_{0}\right)}}{2 \pi G \rho}-\sum_{n=2}^{\infty} \frac{k^{n-1}}{n !} F\left[h^{n}(x)\right]$

The first term of the equation is computed by assigning $h(x)=0$ (Oldenburg 1974) and the first approximation value $h(x)$ from its inverse Fourier transform. The value of $h(x)$ is iteratively used in Eq. (2) to estimate a new value until a reasonable solution is achieved. Because the ParkerOldenburg method is unstable at high frequencies, GómezOrtiz and Agarwal (2005) add a cosine low-pass filter to constraint the high-frequency signals. After a simple test, we set $0.012 \mathrm{~Hz}$ as the corner frequency to deal with the anomalous data.

The above algorithm is applied to compute Moho depth in the Taiwan Strait area $\left(21-27^{\circ} \mathrm{N}\right.$ and $\left.116-122.5^{\circ} \mathrm{E}\right)$ from the regional Bouguer gravity anomaly (Fig. 2), with grid spacing of $5 \mathrm{~km}$. Because of the inherent non-uniqueness of gravity interpretation and a paucity of deeper geological cross-sections, seismic profiles, and velocity tomography in the strait area, an attempt was made to consider the relatively simple assumption that the two parameters of depth and density contrast between the mantle and crust interface. Referred to as the global crustal model (CRUST 5.1 ), a crustal thickness of $30 \mathrm{~km}$ is taken from the worldwide crustal thickness contour map (Mooney et al. 1998). The assumed crustal thickness of $30 \mathrm{~km}$ in this study is in basic agreement with previous literature reports (Kim et al. 2004; Hwang and Yu 2005; Ai et al. 2007), describing a typical old and stable continental crust. In other words, the inverted Moho's relief relative to the average Moho depth of $30 \mathrm{~km}$ is practicable. The common density contrast of $0.6 \mathrm{~g} \mathrm{~cm}^{-3}$ between the mantle and crust interface is appropriate (Dehlinger 1978; Gao and Huang 1994; Yen et al. 1998).

\section{MOHO DEPTH AND DISCUSSIONS}

Convergence of the iterative procedure has been achieved at the sixth iteration, with an RMS error of $0.0157 \mathrm{~km}$. This RMS error, referred to as the RMS error of $0.0157 \mathrm{~km}$ from Gómez-Ortiz and Agarwal (2005), interprets that the inversion result can be acceptable.

Figure 3 shows the Moho depth distribution in the Taiwan Strait area. Its variation is basically consistent with two seismic observations. One is the seismic refraction profile (A-A') offshore of Fuchien Province (Liao et al. 1988). Here, the average Moho depth is about $31 \mathrm{~km}$ except for a change that takes place at $150 \mathrm{~km}$ where a fault cuts through the entire crust (Fig. 4a). The other seismic observation (B-B') along the western coast of Taiwan is obtained from tomographic inversion by jointly using the seismic data set of the CWBSN and two temporary seismic arrays in Hualien and Pingtung (Kim et al. 2005). We assume that the $\mathrm{Vp}=$ $7.5 \mathrm{~km} \mathrm{~s}^{-1}$, taken as the average velocity of three seismic tomography results (Rau and Wu 1995; Ma et al. 1996; Wu et al. 2007), is the discontinued interface between the lower crust and upper mantle. The depth of interface estimated from the velocity structures range from 32 to $34 \mathrm{~km}$ (Fig. $4 \mathrm{~b}$ ). They generally agree with our results calculated from the gravity anomaly. The Moho depth of Penghu uplift is shallower in the Taiwan Strait and thickens toward both sides of

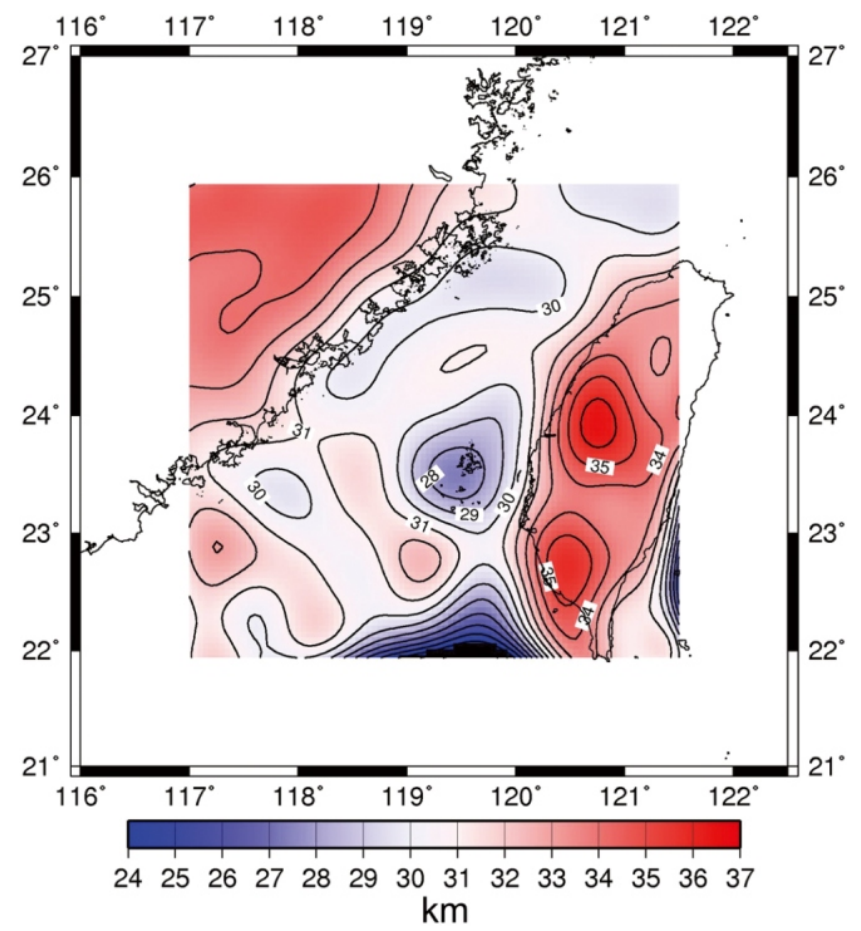

Fig. 3. Moho depth distribution in the Taiwan Strait area derived from the regional Bouguer gravity anomaly data. To avoid edge effects caused by the calculation process, the map is only shown $22-26^{\circ} \mathrm{N}$ and $117-121.5^{\circ} \mathrm{E}$. (Contour interval: $1 \mathrm{~km}$ ) 
the strait (Fig. 4c). The relatively shallower Moho depth, reaching up to $28 \mathrm{~km}$, is convex upward underneath the Penghu uplift. Figure 5 shows the difference between the observed regional gravity anomaly and the gravity anomaly due to the computed 3D Moho relief (by means of the forward modeling algorithm). These differences are at most in the range of -5 to $5 \mathrm{mgal}$ and can be tolerated for the whole

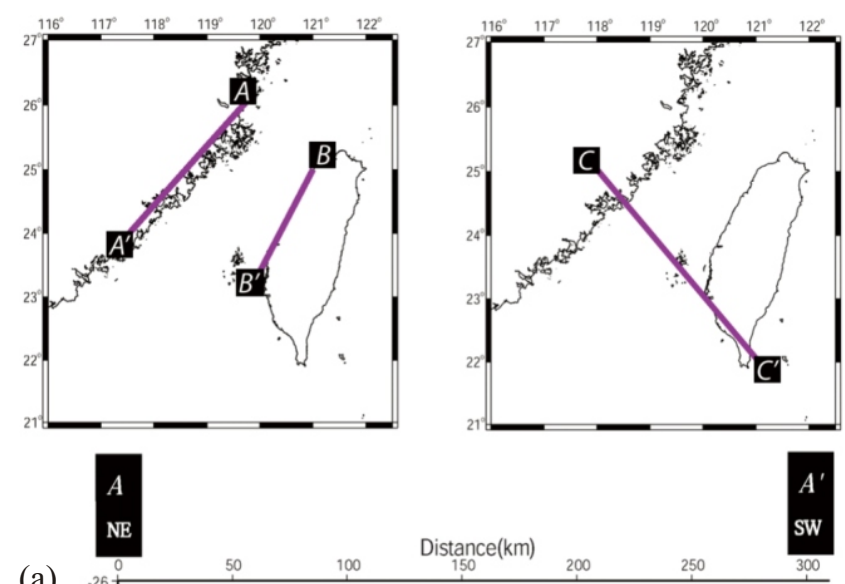

(a)

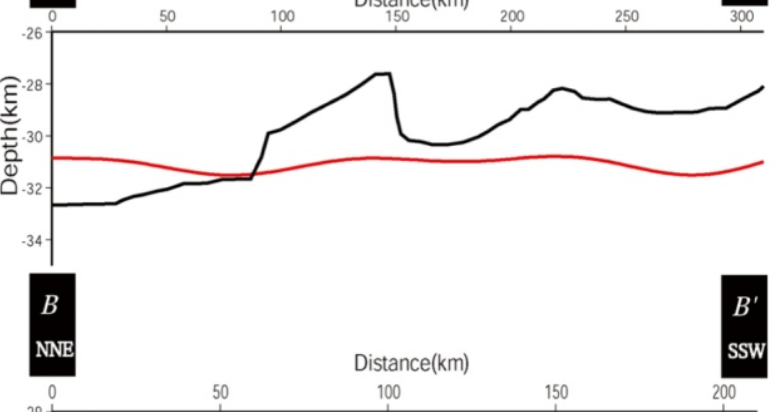

(b)

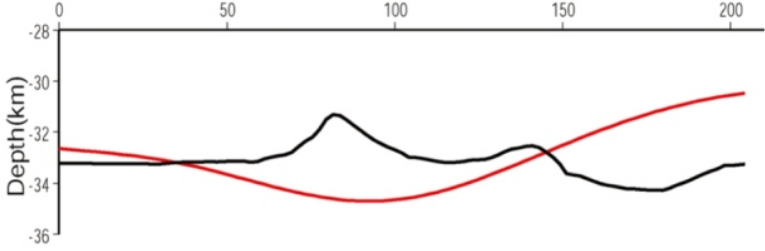

(c)
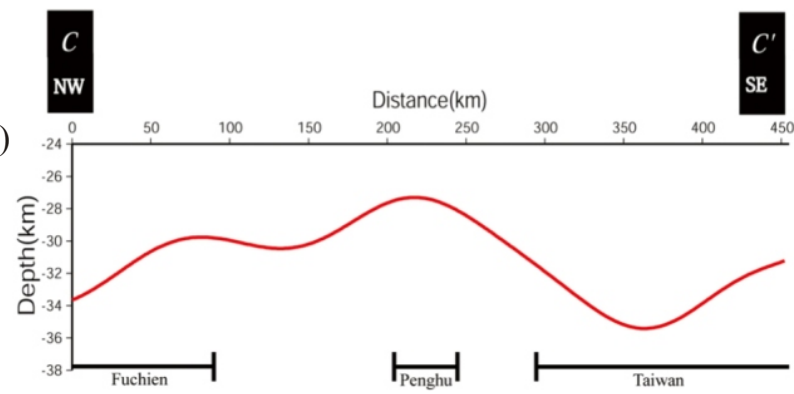

Fig. 4. Locations of three Moho depth profiles (purple lines A-A', B-B', and C-C' at the index map). (a) The average Moho depth (black line) from the seismic refraction survey is about $31 \mathrm{~km}$, except for a fault cutting through the entire crust at a distance of $150 \mathrm{~km}$ (Liao et al. 1988); (b) the Moho depth (corresponds to $\mathrm{Vp}=7.5 \mathrm{~km} \mathrm{~s}^{-1}$, black line) variations referred from the velocity structures (Kim et al. 2005). The Moho depth along the A-A' and B-B' profiles calculated from the gravity data (red line) are basically consistent with two seismic observations; (c) The Moho depth along the C-C' profile across Island Penghu taken from Fig. 3 (red line). strait area. In short, Moho depth distribution in the Taiwan Strait area obtained from the gravity anomaly is acceptable in that the results are generally consistent with two seismic constraints and front evaluation.

Over the strait area, the geometry of the Moho relief is relatively flat with an average depth about $30 \mathrm{~km}$, except for the Penghu uplift. It is conceivable that the crust of the Taiwan Strait can be regarded as a typical old and stable continental crust interior of the southeastern Chinese mainland (part of Eurasian plate) and that it is only slightly deformed as it is far away from the collision boundary. The relatively shallower Moho depth, reaching up to $28 \mathrm{~km}$, is convex upward underneath the Penghu uplift, which may have been caused by magma upwelling. This is consistent with the extensive basalt flows that form the Penghu Island group. Moho depth thins rapidly for southwestern offshore Taiwan (i.e., the southern border of the map).

The Moho depth distribution is shallower for the strait itself and thickens toward both the Fuchien and Taiwan coastal zones. The trend of the convex axis is roughly in a $\mathrm{N}-\mathrm{S}$ direction and nearly perpendicular to the relative motion between the Philippine Sea plate and the Eurasian plate. According to Chung et al. (1994), in the lithosphere section across the Taiwan Strait, the thinnest crust is located at the western part of strait (i.e., between Penghu islands and Fuchien Province). Kao and $\mathrm{Wu}$ (1996) propose that extensional N-S mantle flow under the crust in the Taiwan Strait may have been able to create favorable conditions for

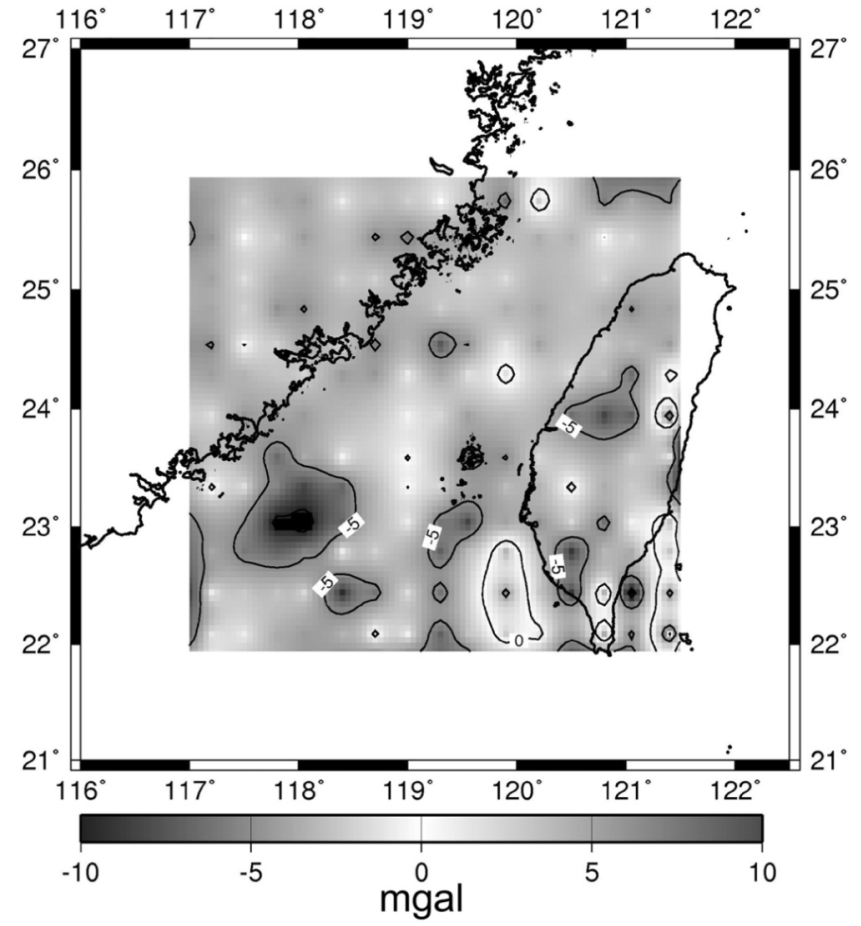

Fig. 5. Difference between the gravity anomaly forward computation of 3D Moho relief and the observed gravity map presented in Fig. $2 \mathrm{~b}$. (Contour interval 5 mgal.) 
a nearly E-W striking normal fault to occur based upon analysis of seismic data, such as the 16 September 1994 Taiwan Strait earthquake (Dziwonski et al. 1995; Zheng et al. 1998). The result for the Moho depth distribution seems consistent with structural evolution of mantle uplift and crust thinning in the Taiwan Strait area. We expect that the $P m P$ data from the forthcoming active seismic experiments of the Taiwan Integrated Geodynamics Research (TAIGER) project will substantiate our gravity findings.

\section{CONCLUSION}

The compiled gravity anomaly map for the Taiwan Strait (Fig. 2a) shows that the trend of the main gravity anomaly is in a NE-SW direction, consistent with the overall shallower geological strike of the strait. Conspicuous negative anomalies occur in Fuchien Province and Western Taiwan; positive anomalies dominate the Taiwan Strait. An anomaly high is over the Penghu islands, where basalt outcrops, and their southern part, with a maximum value of $60 \mathrm{mgal}$. Removing the gravity effects due to sea-water layer and submarine topography, the regional Bouguer gravity anomaly is obtained (Fig. 2b). A remarkable semicircular gravity high trending $\mathrm{N}-\mathrm{S}$ is found from the southern part of the strait to the Penghu islands. This anomalous area, with a maximum value of $180 \mathrm{mgal}$, is most likely caused by the oceanic crust in the south and high-density extrusive basalts in the north.

The Moho relief, computed from a regional Bouguer gravity data set, is relatively flat, except for the Penghu uplift, with an average depth about $30 \mathrm{~km}$. The Moho depth is shallower in the Taiwan Strait and thickens toward its sides. The relatively shallower Moho depth, reaching up to $28 \mathrm{~km}$, is convex upward underneath the Penghu uplift, which may be caused by magma upwelling.

In this study, a thinner crust is obtained in the strait area as compared with those in the southeastern Chinese mainland and Taiwan. This suggests that the crust underneath the Taiwan Strait has been undergoing a structural evolution of mantle uplifting and crustal thinning. Moreover, our results provide an important regional framework for further planning of a large-scale geophysical survey (such as TAIGER project) in the Taiwan Strait area and studies on alternate interactions between the Philippine Sea and Eurasian plates.

Acknowledgements We are indebted to Ta-Liang Teng, Yih-Hsiung Yeh, Guey-Kuen Yu, Cheng-Horng Lin, and Bor-Shouh Huang. The authors express their sincere appreciation to David Gómez-Ortiz and an anonymous reviewer for critical reviews and excellent suggestions on this manuscript. This research was partially supported by the Institute of Earth Sciences, Academia Sinica and the Taiwan Earthquake Research Center (TEC) funded through National Science Council. The TEC contribution number for this article is 00056 .

\section{REFERENCES}

Ai, Y., Q. Chen, F. Zeng, X. Hong, and W. Ye, 2007: The crust and upper mantle structure beneath southeastern China. Earth Planet. Sci. Lett., 260, 549-563.

Chen, A. T. and Y. Nakamura, 1992: Investigating deep crustal structure in the northeastern South China Sea and Taiwan Strait using ocean bottom seismographs. Acta Geol. Taiwan., 30, 145-148.

Chen, X., S. Lin, Z. Li, T. Bao, and Z. Zhou, 2005: Preliminary 1D model for crust velocity structure in Fujian - Taiwan region. Earthquake, 25, 61-68.

Chou, S. L., 1991: Evolution of paleo-structures and hydrocarbons exploration in the Tertiary basins of western Taiwan. Proc. $3^{\text {rd }}$ Taiwan Geophys. Symp., 263-280.

Chung, S. L., S. Sun, K. Tu, C. H. Chen, and C. Y. Lee, 1994: Late Cenozoic basaltic volcanism around the Taiwan Strait, SE China: Product of lithosphere-asthenosphere interaction during continental extension. Chem. Geol., 112, $1-20$.

Dehlinger, P., 1978: Marine Gravity, Elsevier Scientific Publishing Co., Amsterdam, 322 pp.

Dziwonski, A. M., G. Ekstrom, and M. P. Salganic, 1995: Centroid-moment tensor solutions for July-September 1994. Phys. Earth Planet. Inter., 90, 1-11.

Gao, T. and H. Huang, 1994: Tectonic characteristics and evolution of the Taiwan Strait. Acta Geol. Sin., 68, 3, 197-207.

Gómez-Ortiz, D. and B. N. P. Agarwal, 2005: 3DINVER.M: A MATLAB program to invert the gravity anomaly over a 3-D horizontal density interface by Parker-Oldenburg's algorithm. Comput. Geosci., 31, 513-520.

Griffin, W. R., 1949: Residual gravity in theory and practice. Geophysics, 14, 39-56.

Haxby, W. F., 1987: A portrayal of grided geophysical data derived from the SEASAT radar altimeter measurement of the shape of the ocean surface, Report GG-3, National Geophysical Data Center, Boulder, CO., USA.

Hsiao, P. T., C. C. Hu, K. A. Lin, S. H. Hsu, S. C. Fuh, T. Y. Chang, T. A. Hsiuan, H. C. Sheen, C. L. Kuo, and C. J. Lee, 1991: Hydrocarbon potential evaluation of the Penghu basin. Petrol. Geol. Taiwan, 26, 215-229.

Huang, B. S., K. C. Chen, K. L. Wang, and H. Y. Yen, 1998: Velocities of $\mathrm{P}_{\mathrm{n}}$-waves in the Taiwan Strait and its surrounding area from regional earthquakes. Terr. Atmos. Ocean. Sci., 9, 473-486.

Hwang, R. D. and G. K. Yu, 2005: Shear-wave velocity structure of upper mantle under Taiwan from the array analysis of surface waves. Geophys. Res. Lett., 32, L07310, doi: 10.1029/2004GL021868.

Kao, H. and F. T. Wu, 1996: The 16 September 1994 earthquake in Taiwan Strait and its tectonic implications. Terr. Atmos. Ocean. Sci., 7, 13-30.

Kim, K. H., J. M. Chiu, H. Kao, Q. Liu, Y. H. Yeh, 2004: A preliminary study of crustal structure in Taiwan region using receiver function analysis. Geophys. J. Int., 159, 146-164. 
Kim, K. H., J. M. Chiu, J. Pujol, K. C. Chen, B. S. Huang, Y. H. Yeh, and P. Shen, 2005: Three-dimensional VP and VS structural models associated with the active subduction and collision tectonics in the Taiwan region. Geophys. J. Int., 162, 204-220.

Liao, Q., Z. Wang, L. Wang, Z. Yu, N. Wu, and B. Liu, 1988: Explosion seismic study of the crustal structure in Fuzhou - Quanzhou - Shantou region. Chin. J. Geophys., 31, 270280. (in Chinese)

Liu, G. D., 1992: Bouguer gravity anomaly map of China Seas and adjacent regions, The Geological Publishing House Press.

Ma, K. F., J. H. Wang, and D. Zhao, 1996: Three-dimensional seismic velocity structure of the crust and uppermost mantle beneath Taiwan. J. Phys. Earth, 44, 85-105.

Mooney, W. D., G. Marters, and G. Laske, 1998: CRUST 5.1: A global crustal model at $5^{\circ} \times 5^{\circ}$. J. Geophys. Res., 103, 727-747.

Oldenburg, D. W., 1974: The inversion and interpretation of gravity anomalies. Geophysics, 39, 526-536.

Parker, R. L., 1973: The rapid calculation of potential anomalies. Geophys. J. R. Astr. Soc., 31, 447-455.

Rau, R. J. and F. T. Wu, 1995: Tomographic imaging of lithospheric structures under Taiwan. Earth Planet. Sci. Lett., 133, 517-532.

Rosendahl, B. R., 1987: Architecture of continental rifts with special reference to East Africa. Annu. Rev. Earth Planet. Sci., 15, 445-503.

Sun, S. C., 1982: The Tertiary basins of offshore Taiwan. Proceeding $2^{\text {nd }}$ ASCOPE Conference, Manila, 125-135.

Sun, S. C., 1985: The Cenozoic tectonic evolution of offshore Taiwan. Energy, 10, 421-432.
Teng, L. S., 1992: Geotectonic evolution of Tertiary continental margin basins of Taiwan. Petrol. Geol. Taiwan, 27, 1-19.

Wu, Y. M., C. H. Chang, L. Zhao, J. B. H. Shyu, Y. G. Chen, K. Sieh, and J. P. Avouac, 2007: Seismic tomography of Taiwan: Improved constraints from a dense network of strong motion stations. J. Geophys. Res., 112, B08312, doi: 10.1029/2007JB004983.

Yang, K. M., H. H. Ting, and J. Yuan, 1991: Structural styles and tectonic modes of Neogene extensional tectonics in southwestern Taiwan: Implications for hydrocarbon exploration. Petrol. Geol. Taiwan, 26, 1-31.

Yen, H. Y., W. T. Liang, B. Y. Kuo, Y. H. Yeh, C. S. Liu, D. Reed, N. Lundberg, F. C. Su, and H. S. Chung, 1995a: A regional gravity map for the subduction-collision zone near Taiwan. Terr. Atmos. Ocean. Sci., 6, 233-250.

Yen, H. Y., Y. H. Yeh, C. H. Lin, K. J. Chen, and Y. B. Tsai, 1995b: Gravity survey of Taiwan. J. Phys. Earth, 43, 685696.

Yen, H. Y., Y. H. Yeh, and F. T. Wu, 1998: Two-dimensional crustal structures of Taiwan from gravity data. Tectonics, 17, 104-111.

Yu, H. S., 1993: Contrasting tectonic style of a fore deep with a passive margin: Southwest Taiwan and south China. Petrol. Geol. Taiwan, 28, 97-118.

Yu, H. S. and F. W. Huang, 1994: Stratigraphy of Cenozoic sequences in Taiwan Strait and southern East China Sea. Petrol. Geol. Taiwan, 29, 171-192.

Zheng, T. Y., Y. S. Ai, and Q. Z. Chen, 1998: The 16 September 1994 Taiwan Strait earthquake: A simple rupture event starting as a break of asperity. Phys. Earth Planet. Inter., 107, 269-284. 